\title{
Analisis CFD pada Geometri Backward-facing Step dengan variasi Bilangan Reynolds
}

\author{
Steven Darmawan ${ }^{1)^{*}}$, Joshua Nove Octavian ${ }^{2)}$ \\ ${ }^{1,2)}$ Program Studi Teknik Mesin, Universitas Tarumanagara, Jakarta, Indonesia
}

naskah masuk 15/07/2018; diterima 20/10/2018; terbit 29/10/2018 doi: 10.24843/JEM.2018.v11.i02.p07

\begin{abstract}
Abstrak
Sistem tata udara pada bidang perhotelan merupakan salah satu aspek penting untuk menunjang kenyamanan, yang pada daerah pariwisata seperti Bali dengan iklim tropis dilakukan dengan aplikasi pendingin udara (AC). Aliran udara pada hotel bertingkat biasa dibuat terpusat dan dialirkan ke tempat tujuan dengan menggunakan ducting dengan penampang segi empat. Menyesuaikan dengan denah yang ada, seringkali terdapat bagian ducting yang harus dibuat bertingkat pada titik datum yang sama (zona ekspansi). Geometri bertingkat ini dapat menghasilkan kerugian aliran karena pada zona ekspansi tersebut timbul aliran berputar (aliran resirkulasi). Pemahaman terhadap aliran berputar dapat dilakukan dengan lebih mudah, menarik dan berbiaya rendah dengan menggunakan geometri Backward-facing step (BFS). Pada penelitian ini, dilakukan analisis numerik melalui simulasi CFD terhadap aliran resirkulasi pada sebuah geometri backward-facing step, dengan panjang total $(L)=4050$ $\mathrm{mm}$, step height $(h)=41 \mathrm{~mm}$, upstream height $(H)=81 \mathrm{~mm}$, rasio ekspansi $=1.5$, dan lebar $(t)=20 h$. Eksperimen dilakukan dengan fluida kerja asap. Untuk mendapatkan hasil yang lebih luas, eksperimen juga dilakukan pada 3 (tiga) variasi bilangan Reynolds: $\operatorname{Re}=7.315,79 ; \operatorname{Re}=21.947,37$; dan $\mathrm{Re}=29.263,16$. Simulasi CFD dilakukan secara 3 dimensi dengan menggunakan model turbulen RNG $k-\varepsilon$, mesh jenis triangular dengan jumlah nodal sebanyak 36.806 nodal. Vorteks resirkulasi ditunjukkan melalui zona resirkulasi yang direpresentasikan oleh vektor kecepatan arah-x dan titik penyatuan (reattachment point) yang diukur dari zona resirkulasi. Hasil simulasi CFD menunjukkan bahwa vorteks resirkulasi timbul pada $\mathrm{X} / \mathrm{h}=29.2$ hingga $\mathrm{X} / \mathrm{h}=35$ untuk seluruh bilangan Reynolds uji yang direpresentasikan oleh vektor kecepatan arah- $\mathrm{x}$, dimana Reynolds $\mathrm{Re}=7.315,79$ menghasilkan titik penyatuan pada $\mathrm{X} / \mathrm{h}>35$ dari zona resirkulasi, lebih jauh dibandingkan dengan yang dicapai oleh bilangan Reynolds yang semakin besar
\end{abstract}

Kata kunci: Aliran resirkulasi, geometri backward-facing step (BFS), bilangan Reynolds

\section{Abstract}

Air conditioning system is an important aspect in tourism industry that has become a priority sector in Bali, Indonesia. It's tropical climate make the air conditioning system use for cooling system only (AC). The centralized air conditioning system in high rise building uses ducting system with rectangular cross-sectional area which often depends on a given blue print. Some specific area of the blue print may lead to adjustment of the ducting system, e.g. the gradual step of the ducting system. This gradual base of the ducting may cause additional consequences, a recirculation flow at the gradation area (the expansion zone). As already known, the recirculation flow leads to flow losses. This paper discuss an numerical analysis with CFD simulation of a backward-facing step (BFS) geometry. The BFS geometry used in this has total length $(\mathrm{L})=4050 \mathrm{~mm}$, step height $(\mathrm{h})=41 \mathrm{~mm}$, upstream height $(H)=81 \mathrm{~mm}$, expansion ratio $=1.5$, and width $(\mathrm{t})=20 \mathrm{~h}$. The CFD simulation conducted three dimensionaly with RNG $k-\varepsilon$ turbulence model, and 36.806 triangular nodes. Recirculation vortices represented by recirculation zone with $x-$ velocity and reattachment point. The result of CFD simulation that is conducted to Reynolds number $\mathrm{Re}=7.315,79 ; \mathrm{Re}=$ 21.947,37; dan $R e=29.263,16$ shows that recirculation vortices occur at $X / h=29,2$ to $X / h=35$ for tested Reynolds number. Reattachment point at Reynolds number of 7.315 .79 occur at $\mathrm{X} / \mathrm{h}>35$, which farther than that is achieved at larger Reynolds number.

Keywords: Recirculation flow, Backward-facing step (BFS) geometry, Reynolds number

\section{Pendahuluan}

Sistem tata udara pada bidang perhotelan merupakan salah satu aspek penting untuk menunjang kenyamanan, yang pada daerah pariwisata seperti Bali dengan iklim tropis dilakukan dengan aplikasi pendingin udara (AC). Aliran udara pada hotel biasa dibuat terpusat dan dialirkan ke tempat tujuan dengan menggunakan ducting dengan penampang segi empat.

Namun untuk menyesuaikan dengan denah yang ada, seringkali terdapat bagian ducting yang harus dibuat belok atau bertingkat. Geometri bertingkat ini dapat menghasilkan rugi-rugi aliran karena terbentuknya zona dimana geometri berubah secara mendadak atau disebut sebagai zona ekspansi. Fluida yang melewati zona ekspansi secara umum menyebabkan timbulnya vorteks resirkulasi dan titik penyatuan (reattachment point) serta melibatkan perpindahan panas selama proses aliran tersebut. Penelitian terkait aliran berputar pada geometri BFS pada ducting dan komponen mekanikal lain yang telah banyak dilakukan [1], [2], [3], [4], [5], [6] Aliran berputar dapat dilakukan dengan lebih mudah, menarik dan berbiaya rendah dengan menggunakan geometri Backward-facing step (BFS).

Aliran berputar merupakan jenis aliran yang rumit karena adanya vortex resirkulasi yang dipengaruhi oleh geometri, perbedaan temperatur dan kecepatan alir. 


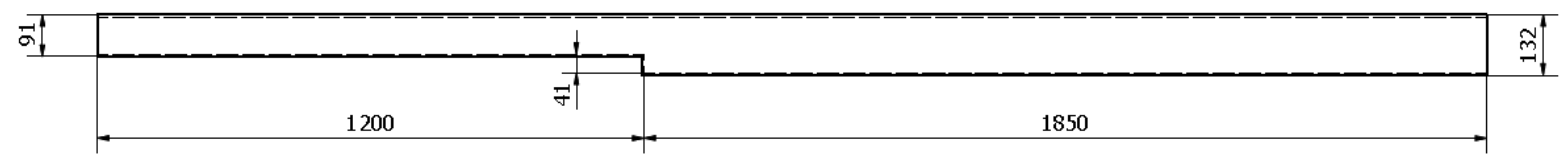

Gambar 1. Gambar Kerja Geometri BFS

Fenomena ini sulit untuk dipahami karena beberapa hal antara lain keterbatasan alat uji dan perilaku vorteks resirkulasi. Geometri BFS merupakan geometri acuan sederhana yang sering digunakan untuk meneliti vorteks resirkulasi. Namun, penelitianpenelitian yang menggunakan BFS seringkali terhambat karena kebutuhan teknologi yang harus mumpuni, baik untuk fluida cair atau gas, sehingga metode penelitian bentuk lain seperti penggunaan metode CFD dibutuhkan sehingga penelitian vorteks resirkulasi dapat dikembangkan [7], [8], [9]

Penelitian ini dilakukan untuk memvisualisasikan aliran berputar pada geometri BFS pada variasi Bilangan Reynolds dengan menggunakan metode CFD dengan fluida kerja udara ( 1 fasa) pada variasi bilangan Reynolds sehingga karakteristik aliran berputar dapat semakin dipahami.

\section{Metode Penelitian}

\subsection{Geometri Backward-facing step}

Meskipun geometri Backward-facing step (BFS) banyak digunakan untuk penelitian terkait aliran berputar, namun parameter-parameter dimensi yang tidak baku menjadi tantangan khusus dalam penelitian yang menggunakan geometri ini [10]. Maka penelitian ini menggunakan geometri BFS dari [11] Tabel 1. Gambar kerja dari geometri BFS ditunjukkan oleh Error! Reference source not found.

Tabel 1. Geometri BFS - revisi [11]

\begin{tabular}{|c|c|c|c|c|}
\hline \multicolumn{5}{|c|}{ Geometri Backward-facing step } \\
\hline $\begin{array}{c}\text { Step } \\
\begin{array}{c}\text { Height } \\
(\text { h) } \\
(\mathrm{mm})\end{array}\end{array}$ & $\begin{array}{c}\text { Upstream } \\
\text { height (H) } \\
(\mathrm{mm})\end{array}$ & $\begin{array}{c}\text { Rasio } \\
\text { Ekspansi }\end{array}$ & $\begin{array}{c}\text { Panjang } \\
\text { total (L) } \\
\text { mm }\end{array}$ & $\begin{array}{c}\text { Panjang } \\
\text { total (L) } \\
\text { mm, + } \\
\text { konektor }\end{array}$ \\
\hline $\begin{array}{c}41 \\
\text { Width } \\
(\mathrm{mm})\end{array}$ & 81 & 1,5 & $82,5 \mathrm{H}$ & 4050 \\
\hline \multicolumn{5}{|c|}{$20 \mathrm{~h}$} \\
\hline
\end{tabular}

\subsection{Simulasi CFD}

Untuk dapat menghasilkan visualisasi yang baik terhadap aliran berputar di geometri BFS, simulasi CFD secara tiga dimensi dilakukan dengan menggunakan Autodesk CFD 2017, academic version sesuai dengan geometri yang ditunjukkan oleh Error! Reference source not found.. Fluida kerja yang digunakan pada simulasi adalah udara (1 fasa) dengan asumsi temperature $26,1^{\circ} \mathrm{C}$ dan tekanan kerja $101.300 \mathrm{~N} / \mathrm{m}^{2}$. Dengan asumsi kondisi operasi yang stabil dan tanpa reaksi, simulasi dilakukan dengan keadaan tunak. Aliran berputar yang terjadi pada zona ekspansi geometri BFS direpresentasikan oleh kecepatan arah- $\mathrm{x}\left(\mathrm{v}_{\mathrm{x}}\right)$ pada nodal-y pertama sepanjang arah-x seperti yang ditunjukkan zona analisis pada Error! Reference source not found.

Jenis mesh merupakan jenis triangular berjumlah 36.806 nodal. Karena kesesuaiannya dengan karakteristik aliran berputar, simulasi CFD dilakukan dengan menggunakan model turbulen RNG $k-\varepsilon$ [12], [13], [14], [15].

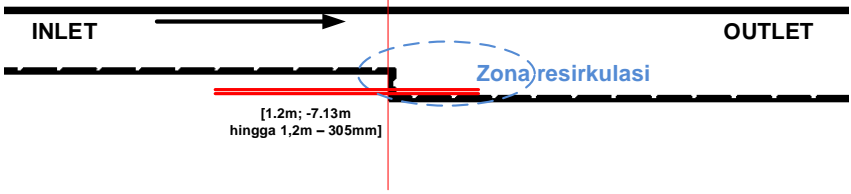

Gambar 2. Zona analisis

\subsection{Validasi Model Simulasi}

Validasi terhadap model simulasi CFD pada geometri BFS telah dilakukan pada penelitian sebelumnya dengan menggunakan fluida kerja asap untuk eksperimen dan model turbulen RNG k- $\varepsilon$ untuk metode numerik (CFD). Mesh yang digunakan berupa triangular sebanyak 36.806 nodal. Dengan parameter validasi $\mathrm{X} / \mathrm{h}$ dan bilangan Reynolds masuk $\mathrm{Re}=$ $14.361,58$, hasil yang diperoleh melalui CFD simulasi $\mathrm{X} / \mathrm{h}=1.18$ dibandingkan dengan hasil eksperimen $\mathrm{X} / \mathrm{h}$ $=1.02[16]$.

\section{Hasil dan Pembahasan}

Simulasi CFD telah dilakukan pada geometri BFS dengan variasi bilangan Reynolds. Visualisasi aliran berputar dilakukan pada 2 (dua) parameter utama, yaitu kecepatan arah- $\mathrm{x}\left(\mathrm{v}_{\mathrm{x}}\right)$ dan titik penyatuan (reattachment point). Panjang saluran pada sisi upstream ditentukan berdasarkan perhitungan terhadap kebutuhan jarak aliran berkembang penuh.

\subsection{Profil kecepatan}

Intensitas vorteks resirkulasi pada geometri BFS direpresentasikan oleh kecepatan arah-x, seperti yang ditunjukkan oleh Error! Reference source not found. hingga Error! Reference source not found. untuk bilangan Reynolds $R e=7315.79 ; R e=21.947,37$; dan $\mathrm{Re}=29.263,16$ secara berturut-turut. Vektor kecepatan pada ketiga variasi bilangan Reynolds ditunjukkan oleh Error! Reference source not found. secara berurutan. Tampak bahwa intensitas vorteks resirkulasi pada zona resirkulasi semakin intens pada bilangan Reynolds yang semakin besar, sesuai dengan yang diperoleh oleh J. Kostas et.al [9].

Hasil simulasi CFD menunjukkan terjadinya aliran resirkulasi di zona ekspansi yang dilanjutkan dengan 
titik penyatuan, menuju sisi keluar. Berdasarkan grafik antara parameter $\mathrm{X} / \mathrm{h}$ dan $\mathrm{V}_{\mathrm{x}}$ pada Error! Reference source not found. dapat dilihat bahwa aliran resirkulasi terjadi pada $\mathrm{X} / \mathrm{h}=29,2$ hingga $\mathrm{X} / \mathrm{h}=35$ (zona ekspansi) berdasarkan zona analisis yang ditunjukkan oleh Error! Reference source not found.. Pada titik tersebut, kecepatan fluida kera arah$\mathrm{x}\left(\mathrm{v}_{\mathrm{x}}\right)$ ditunjukkan oleh Error! Reference source not found., dimana intensitas aliran resirkulasi semakin besar pada bilangan Reynolds yang semakin besar.

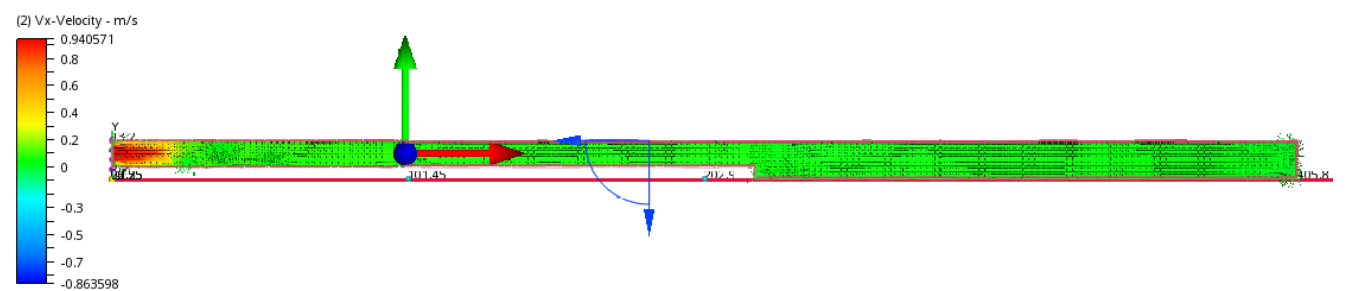

Gambar 3. Kontur kecepatan arah-x; $\mathrm{Re}=7.315,79(\mathrm{Vx})$

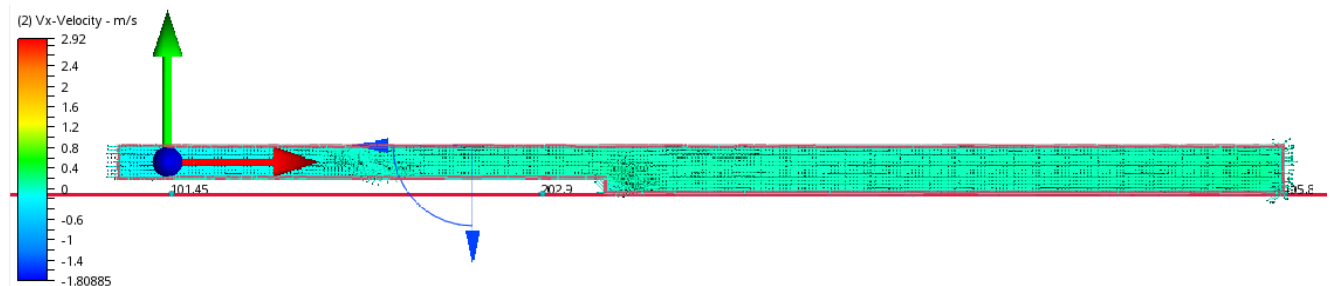

Gambar 4. Kontur kecepatan arah-x; $\mathrm{Re}=21.947,37$ (Vx)

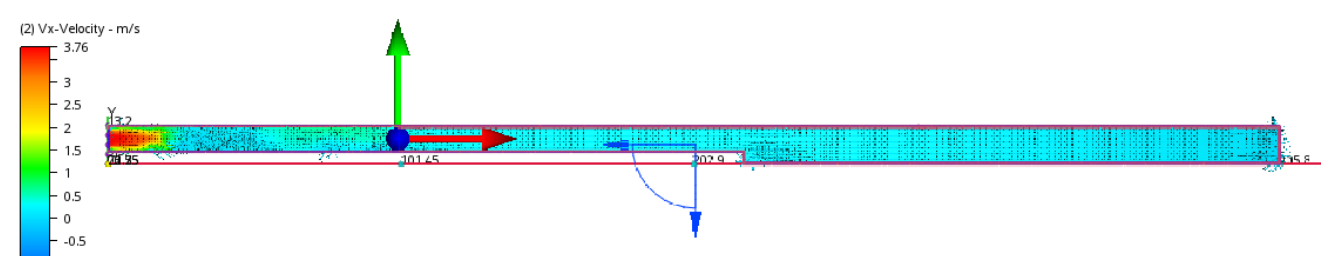

Gambar 5. Kontur kecepatan arah-x; $\mathrm{Re}=29.263,16(\mathrm{Vx})$
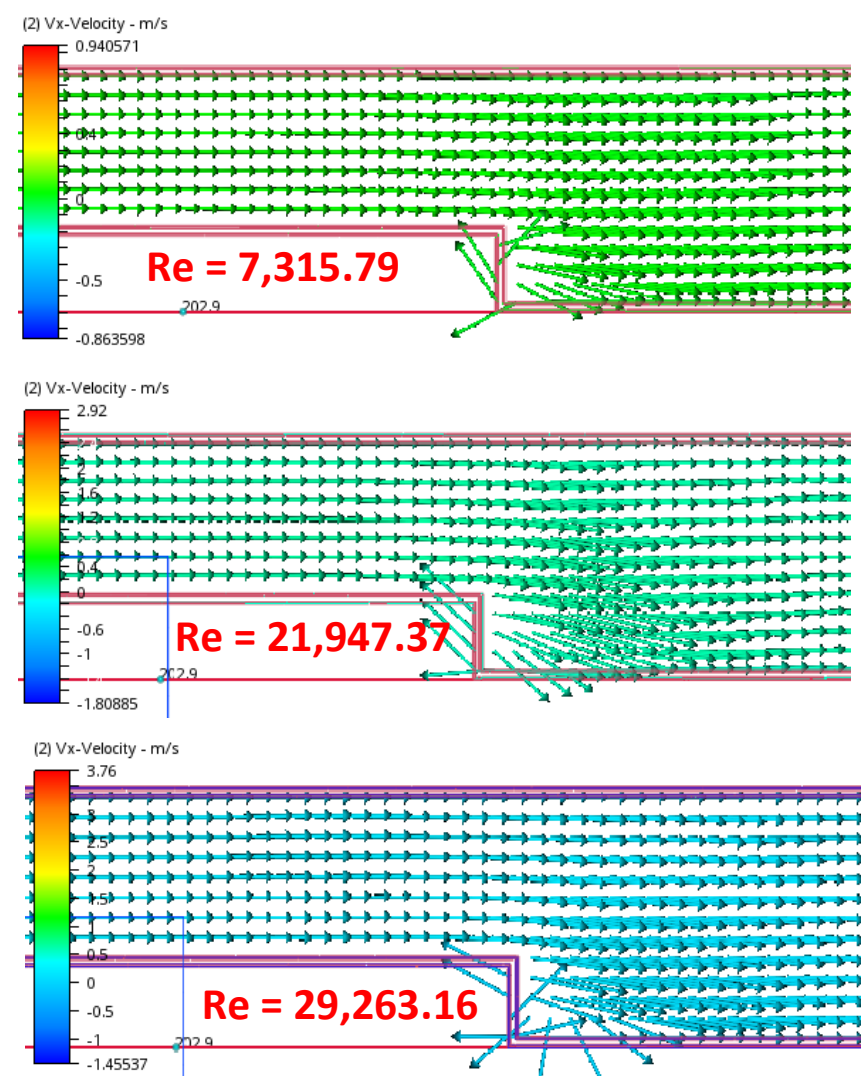

Gambar 6. Vektor Kecepatan - x pada zona resirkulasi pada variasi bilangan Reynolds 


\subsection{Titik Penyatuan}

Berakhirnya zona resirkulasi yang ditandai dengan stabilitas aliran yang meningkat terjadi pada titik penyatuan (reattachment point). Lokasi tersebut di karakterisasi dengan menggunakan parameter takberdimensi $\mathrm{X} / \mathrm{h}$ pada komponen kecepatan - $\mathrm{x}$, dimana $X$ merupakan arah mendatar dan $\mathrm{h}$ merupakan tinggi langkah. Setelah bersirkulasi, kecepatan aliran akan terus menurun secara bertahap menuju sisi keluar. Berdasarkan hasil analisis Besarnya $\mathrm{v}_{\mathrm{x}}$ pada lokasi tersebut ditunjukkan oleh Error! Reference source not found..

Tabel 2. Nilai $v_{x}$ pada $X / h=29.2$

\begin{tabular}{|c|c|c|c|}
\hline \multirow{3}{*}{$\mathbf{X} / \mathbf{h}$} & $\mathbf{R e}$ & $\mathbf{R e}$ & $\mathbf{R e}$ \\
& $\mathbf{7 3 1 5 . 7 9}$ & $\mathbf{2 1 9 4 7 . 3 7}$ & $\mathbf{2 9 2 6 3 . 1 6}$ \\
\cline { 2 - 4 } & $\mathbf{V}_{\mathbf{x}}(\mathbf{m} / \mathbf{s})$ & $\mathbf{V}_{\mathbf{x}}(\mathbf{m} / \mathbf{s})$ & $\mathbf{V}_{\mathbf{x}}(\mathbf{m} / \mathbf{s})$ \\
\hline 29.2 & $-1.66 \mathrm{E}-04$ & $-2.07 \mathrm{E}-02$ & $-1.20 \mathrm{E}-02$ \\
\hline
\end{tabular}

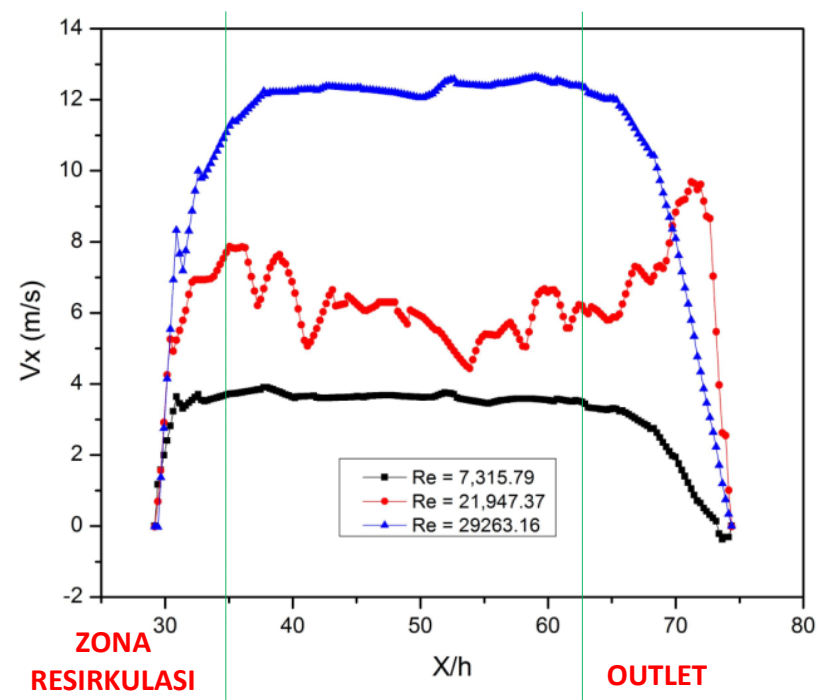

Gambar 7. Grafik kecepatan arah-x pada X/h

Error! Reference source not found. dengan kecepatan arah- $\mathrm{x} \mathrm{v}_{\mathrm{x}}$ merupakan fungsi dari $\mathrm{X} / \mathrm{h}$, titik penyatuan untuk ketiga variasi bilangan Reynolds dicapai pada $X / h=35$, dimana titik penyatuan semakin jauh dari zona resirkulasi pada bilangan Reynolds yang semakin kecil dengan $\mathrm{X} / \mathrm{h}>35$. Pengurangan nilai h dapat mereduksi lokasi penyatuan [17].

Secara umum, seperti yang ditunjukkan oleh profil kecepatan pada geometri Backward-facing step terdiri dari 3 (tiga) bagian, yaitu pada zona resirkulasi, zona penyatuan dan zona keluar. Hal ini juga menunjukkan bahwa kenaikan bilangan Reynolds tidak linier dengan profil kecepatan arah-x yang terjadi pada geometri. Secara umum, bilangan Reynolds $R e=29.263,16$ menunjukkan hasil yang paling stabil dibandingkan dengan yang dihasilkan oleh bilangan Reynolds lain.

\section{Simpulan}

Simulasi CFD pada geometri Backward-facing step (BFS) telah dilakukan pada 3 (tiga) bilangan Reynolds, yaitu $R e=7.315,79 ; R e=21.947,37$; dan
$\mathrm{Re}=29.263,16$ dengan menggunakan fluida kerja udara. Analisis terhadap hasil simulasi tersebut sebagai berikut:

a. Vorteks resirkulasi timbul pada $X / h=29.2$ hingga $\mathrm{X} / \mathrm{h}=35$ untuk seluruh bilangan Reynolds uji yang direpresentasikan oleh vektor kecepatan arah-x.

b. Simulasi dengan bilangan Reynolds $R e=7.315,79$ menghasilkan titik penyatuan pada X/h > 35 dari zona resirkulasi, lebih jauh dibandingkan dengan yang dicapai oleh bilangan Reynolds yang semakin besar.

c. Simulasi dengan bilangan Reynolds $\mathrm{Re}=$ 29.263,16 menunjukkan hasil yang paling stabil dibandingkan dengan yang dihasilkan oleh bilangan Reynolds lain.

\section{Ucapan Terima Kasih}

Penulis mengucapkan terima kasih kepada Direktorat Penelitian dan Pengabdian Kepada Masyarakat Universitas Tarumanagara atas pendanaan penelitian ini melalui skema Hibah Penelitain Internal 2018 Periode 1.

\section{Daftar Pustaka}

[1] J. H. Nie and B. F. Armaly, "Three-dimensional convective flow adjacent to backward-facing step - Effects of step height," Int. J. Heat Mass Transf., vol. 45, no. 12, pp. 2431-2438, 2002.

[2] $\mathrm{H}$. Togun et al., "Thermal performance of nanofluid in ducts with double forward-facing steps," J. Taiwan Inst. Chem. Eng., vol. 47, pp. 28-42, 2015.

[3] W. A. Xie and G. N. Xi, "Fluid flow and heat transfer characteristics of separation and reattachment flow over a backward-facing step," Int. J. Refrig., vol. 74, pp. 175-187, 2017.

[4] F. Selimefendigil and H. F. ت̈¿ ${ }^{1 / 2 z t o p, ~ " F o r c e d ~}$ convection and thermal predictions of pulsating nanofluid flow over a backward facing step with a corrugated bottom wall," Int. J. Heat Mass Transf., vol. 110, pp. 231-247, 2017.

[5] H. Iwai, K. Nakabe, and K. Suzuki, "Flow and heat transfer characteristics of backward-facing step laminar flow in a rectangular duct," Int. J. Heat Mass Transf., vol. 43, no. 3, pp. 457-471, 2000.

[6] K. Sarker, "Computational Analysis of the Physics of Flow over Backward / Forward Facing Step," vol. 11, no. 8, pp. 5549-5554, 2016.

[7] A. Kitoh, K. Sugawara, H. Yoshikawa, and T. Ota, "Expansion Ratio Effects on ThreeDimensional Separated Flow and Heat Transfer Around Backward-Facing Steps," J. Heat Transfer, vol. 129, no. 9, p. 1141, 2007.

[8] A. Keating, U. Piomelli, K. Bremhorst, and S. Nešić, "Large-eddy simulation of heat transfer downstream of a backward-facing step," $J$. Turbul., vol. 5, no. 04, pp. 1-27, 2004.

[9] M. S. Kostas, J; Soria, J; Chong, "A Study of a Backward Facing Step Flow at Two Reynolds 
Numbers," in 14th Australian Fluid Mechanics Conference, 2001, pp. 609-612.

[10] N. Kasagi and A. Matsunaga, "3-D particletracking velocimetry measurement of turbulence statistics and energy budget in a backward-facing step flow (Kasa.pdf," no. 1989, 1993.

[11] S. Darmawan, "LAPORAN AKHIR HIBAH RISET INTERNAL 2016 DIREKTORAT PENELITIAN DAN LAPORAN AKHIR HIBAH RISET INTERNAL 2016," 2017.

[12] V. Yakhot and S. A. Orszag, "Renormalization group analysis of turbulence. I. Basic theory," J. Sci. Comput., vol. 1, no. 1, pp. 3-51, 1986.

[13] S. Thangam and C. G. Speziale, "Turbulent Separated Flow past a Backward-Facing Step: a Critical Evaluation of Two-Equation Turbulence Models," no. 91, p. 28, 1991.

[14] S. Thangam, "Ad-a240 683," no. 91, 1991.

[15] S. Darmawan et al., "Turbulent flow analysis in auxiliary cross-flow runner of a Proto $X-3$ Bioenergy micro gas turbine using RNG $\mathrm{K}-\varepsilon$ turbulence model," ARPN J. Eng. Appl. Sci., vol. 10, no. 16, 2015.

[16] S. Darmawan, "EXPERIMENTAL STUDY OF SMOKE OVER A BACKWARD-FACING STEP GEOMETRY," in The 3rd International Conference on Engineering of Tarumanagara (ICET) 2017, 2017.

[17] Y. T. Chen, J. H. Nie, B. F. Armaly, and H. T. Hsieh, "Turbulent separated convection flow adjacent to backward-facing step-effects of step height," Int. J. Heat Mass Transf., vol. 49, no. 19-20, pp. 3670-3680, 2006.

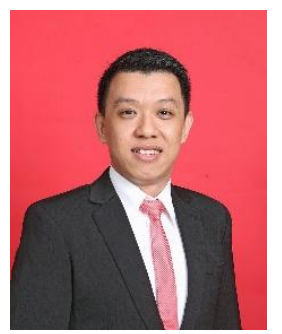

Steven Darmawan menyelesaikan pendidikan S1 Teknik Mesin di Universitas Tarumanagara. Pendidikan magister Teknik Mesin diselesaikan di Universitas Indonesia pada tahun 2011 dengan area riset tentang computational fluid dynamics (CFD). Pada tahun 2015 ia menyelesaikan pendidikan doktoral di Teknk Mesin Universitas Indonesia dengan area riset Computational Fluid Dynamics. Saat ini ia bekerja sebagai dosen di Program Studi Teknik Mesin Universitas Tarumanagara. Bidang penelitian utama yang digeluti adalah CFD, mekanika fluida dan internal combustion engine. 